\title{
Correction to: Calculus for Teachers: Perspectives and Considerations of Mathematicians
}

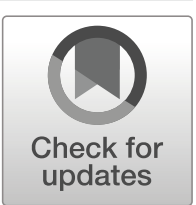

\author{
Xiaoheng Yan • Ofer Marmur • Rina Zazkis
}

Published online: 13 June 2020

(C) Ontario Institute for Studies in Education (OISE) 2020

\section{Correction to: Can. J. Sci. Math. Techn. Educ. https://doi.org/10.1007/s42330-020-00090-x}

In the section titled On the Worth of Calculus for Calculus Per Se in the original article, in the fourth paragraph the sum of the reciprocals squared $\left[\sum_{n=1}^{\infty} \frac{1}{n^{2}}=\frac{1}{1^{2}}+\frac{1}{2^{2}}+\frac{1}{3^{2}}+\cdots\right]$ should read as follows: Euler found an expression for the value of it - it is equal to $\frac{\pi^{2}}{6}$

Publisher's Note Springer Nature remains neutral with regard to jurisdictional claims in published maps and institutional affiliations.

The online version of the original article can be found at https://doi.org/10.1007/s42330-020-00090-x

X. Yan $(\bowtie) \cdot$ O. Marmur $\cdot$ R. Zazkis

Faculty of Education, Simon Fraser University, Burnaby, BC, Canada

e-mail: xkyan@sfu.ca

O. Marmur

e-mail: omarmur@sfu.ca

R. Zazkis

e-mail: zazkis@sfu.ca 